\title{
Impacto da Iniciação Científica na Pós-Graduação
}

\section{Paula B. Silva*, Adriana Bin, Luiza Capanema}

\begin{abstract}
Instruments to foster undergraduation research were developed and institucionalized in Brazil a few decades ago by CNPq and FAPs, with the intention of involving undergraduate students in the development of scientific and technological research in universities and research institutes. The present research aims to analyze the impact of undergraduation research on the academic career of students during and after graduation, using data from a previous work that evaluated undergraduate, master and $\mathrm{PhD}$ scholarship programs from São Paulo Research Foundation (FAPESP). The study concluded that undergraduation research has positive impacts on the academic career of students during and after graduation.
\end{abstract}

\section{Key words:}

Undergraduation research, graduation, impact evauation

\section{Introduction}

Since its foundation, FAPESP has already granted 44,325 undergraduate research scholarships, while CNPq is responsible for the distribution of approximately 20,000 scholarships per year. It represents a significant amount of financial resources and graduated individuals with research experience in Brazil and also potential impacts in multiple dimensions. In this context, the present research aims to analyze the impact of undergraduation research on the academic career of students during and after graduation, using data from a previous work that evaluated undergraduate, master and PhD scholarship programs from FAPESP.

\section{Results and Discussion}

Based on literature review, this study verified six hypotheses.

1) Individuals conducting research during undergraduation are more likely to pursue graduate studies than those who do not have undergraduate research experience;

2) Individuals conducting research during undergraduation are more likely to pursue a professional trajectory involving research activities than those who do not have undergraduate research experience;

3) The graduate achievement by individuals who completed undergraduate research is not influenced by income.

4) The accomplishment of the graduation for individuals that realized research in the graduation is influenced by the area of the knowledge.

5) Individuals conducting research during undergraduate studies hold masters and doctorates in less time than those who did not do research during undergraduation.

6) Individuals conducting research during graduation publish more and in higher quality journals than those who did not do research during graduation.

\section{Conclusions}

Based on our sample, we concluded that undergraduate research has a significant influence on several aspects of academic career, with emphasis on: a) further training in master and doctorate programs; b) performing research as a professional activity; c) less time to master or doctorate completion; and d) publications (count and quality). It is also possible to notice that income and knowledge fields do not have influence on further training of those performing research during undergraduation.

\section{Acknowledgement}

- Sponsor Institution: PIBIC/CNPq 